\title{
O Dia INTERNACIONAL DA MULHER NA PERSPECTIVA DISCURSIVA DO PRESIDENTE BRASILEIRO, LUIZ INÁCIO LULA DA SILVA
}

Luciana Panke ${ }^{l}$

Universidade Federal do Paraná-Brasil panke@ufpr.br

Recibido: 20-02-09

Aceptado: 01-03-09

\section{Resumo}

O artigo apresenta a análise dos discursos do Presidente da República do Brasil, Luiz Inácio Lula da Silva, nas comemorações do Dia Internacional da Mulher entre os anos de 2003 e 2009. O corpus compreende dez pronunciamentos oficiais, enfocando a estrutura argumentativa, cujo principal aparato teórico se encontra na Teoria da Argumentação de Chaim Perelman (1996). Objetivou-se observar como a mulher é retratada nos discursos presidenciais e, se houve alteração neste perfil no decorrer dos dois mandatos de Lula.

Palavras-chave: discurso político; Lula; mulher; Brasil; comunicação.

\begin{abstract}
This article presents the analysis of the President of Brazilian Republic Luiz Inácio Lula da Silva speeches, on International Women's Day celebrations, between 2003 and 2009.

\footnotetext{
${ }^{1}$ Luciana Panke é doutora em Ciências da Comunicação pela Universidade de São Paulo, professora adjunta do Departamento de Comunicação Social da Universidade Federal do ParanáBrasil e pesquisadora integrante do Grupo de Pesquisa Mídia, Linguagem e Educação (Meduc www.meduc-ufpr.org).
} 
The corpus comprises ten official declarations, looking at the structure of reasoning, of which the main theoretical instrument relies in Chaïm Perelman's Theory of Argumentation (1996). The aim was observing how woman is pictured in presidential speeches and if there were any changes in this profile in the elapsing of the two Lula mandates.

Keywords: political speech, Lula; women; Brazil; communication.

\section{Breve contextualização}

Lula, enquanto objeto de estudo acadêmico, suscita curiosidade pelos traços distintivos do personagem: retirante nordestino, família humilde, sindicalista, metalúrgico e pouca escolaridade. Ele é o primeiro civil sem formação universitária a se eleger Presidente, na $19^{\mathrm{a}}$ eleição direta para o cargo, entre as 27 já realizadas desde 1891. Hoje, encontra-se no segundo mandato, que termina em 2010. É conhecido mundialmente, em um primeiro momento, pelas características de sua eleição e no decorrer de seu governo, pela capacidade de articulação no cenário internacional.

Importante salientar que Luiz Inácio Lula da Silva foi eleito no $2^{\circ}$ turno, em ambas as eleições, nos anos de 2002 e 2006. No primeiro pleito, com praticamente 53 milhões de votos (61,3\% dos votos válidos) e na reeleição somou mais de 58 milhões (60,83\% dos votos válidos). Reeleito até 2010, além do cumprimento das expectativas geradas, Lula tem o desafio de manter um alto índice de popularidade inédito no País.

A sua projeção pública deve-se ao histórico vinculado ao Partido dos Trabalhadores (PT), o qual ajudou a fundar na década de 80. O Partido estruturou-se com base na defesa dos direitos da classe trabalhadora em geral, assalariada e dos grupos excluídos pelo sistema econômico. 


\section{Teoria da Argumentação}

As pesquisas desenvolvidas sobre os discursos argumentativos podem demonstrar a força da palavra que exerce poder à medida que dimensiona o mundo, ordena os fatos e apresenta enfoques da realidade. A argumentação vai desencadear essa ordenação, por indução ou dedução, ao transmitir o pensamento, as ideologias e os recortes de mundo.

A Teoria da Argumentação, também denominada como Nova Retórica, trata de uma linha de pesquisa sobre a retórica que tenta compreender o funcionamento das falas persuasivas. A retórica clássica, então, desacreditada por se basear em fatores estéticos e não na fidelidade das informações veiculadas, voltou a ser debatida. Proposta pelo belga Chaïm Perelman, a teoria defende a possibilidade de uma argumentação, cujo "objeto seria o estudo dos meios de argumentação, não pertencentes à lógica formal, que permitem obter ou aumentar a adesão de outrem às teses que se lhe propõem ao seu assentimento" (Perelman, 1997: 57).

É justamente na tradição retórica e dialética grega que Perelman e Tyteca (1996) se baseiam para defender a Nova Retórica no Tratado da Argumentação, onde rompem com a noção de razão, originária em Descartes, que dominou a filosofia ocidental nos últimos três séculos. Com ela, a lógica desacreditava tudo o que não pudesse ser provado com a demonstração, principalmente no século XIX e início do $\mathrm{XX}$, quando o estudo da lógica formal se destacou com o auxílio da matemática, na comprovação de teoremas. Para Descartes, todo verossímil era considerado falso e a evidência se tornou a marca maior da razão por corresponder à verdade provada com demonstrações. Na Nova Retórica admite-se argumentar com base em argumentos baseados no empirismo, em valores e em abstrações.

Os argumentos estão inseridos em um processo de enunciação o que significa que serão entendidos em um contexto estabelecido e por uma comunidade unida lingüisticamente. Primeiramente, é preciso considerar a argumentação como integrante de um processo comunicativo entre as pessoas. Nessa perspectiva, é a situação em que a 
argumentação está inserida que vai lhe conferir o significado pretendido. Dessa forma, pode-se afirmar que o processo argumentativo comporta uma plasticidade inerente ao próprio ato comunicativo porque transita por elementos constitutivos básicos, como dois interlocutores, códigos, decodificação, ruídos, contexto ou feedback. A não linearidade resulta na plasticidade, quando a argumentação está sujeita aos elementos que a constituem.

Os elementos pertencentes ao discurso interagem, desencadeando, através das estratégias argumentativas, o conhecimento que o locutor tem do auditório e as premissas estabelecidas. Por isso, não há como dissociar auditório, acordos e técnicas do contexto porque a argumentação faz parte de um processo sociolingüístico. Apesar de não se dedicar enfaticamente ao estudo do contexto, Perelman observa que "os termos utilizados, seu sentido, sua definição, só são compreendidos no contexto fornecido pelos hábitos, pelos modos de pensar, pelos métodos, pelas circunstâncias exteriores e pelas tradições conhecidas dos usuários" (Perelman, 1996: 580).

Na Nova Retórica, o esquema argumentativo é composto, estruturalmente, por auditório, acordos e técnicas, originários de ARISTÓTELES, que previa a esquematização em orador - discurso - auditório.

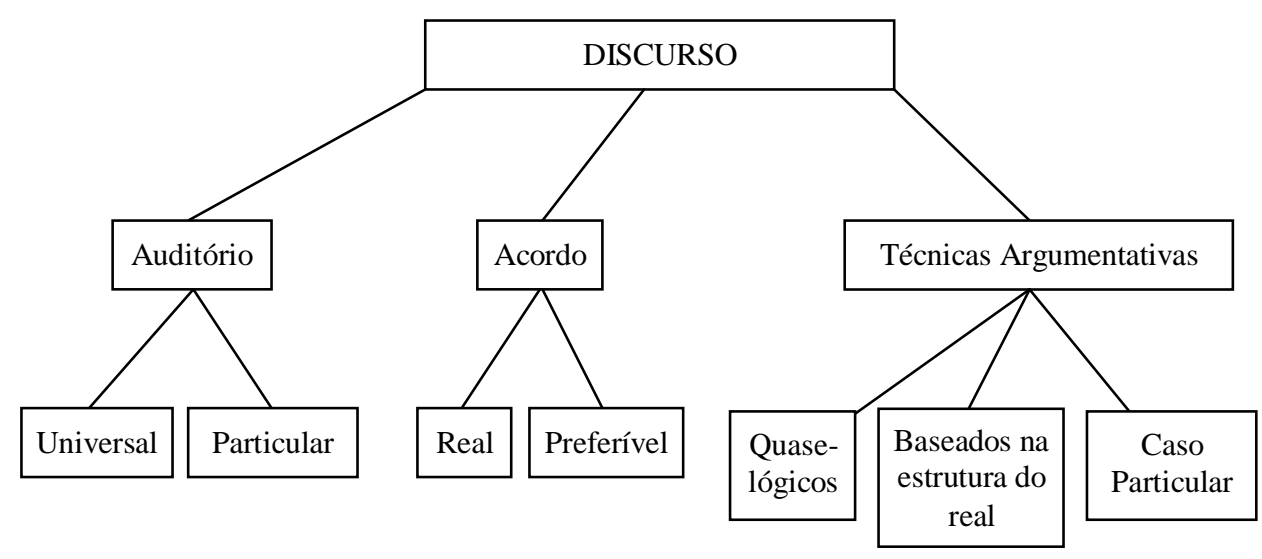

Figura 1 - Esquema básico de Perelman 
O esquema acima se refere ao estágio inicial da teoria. Posteriormente, acordos e técnicas recebem outras subdivisões. O conceito de auditório se centra na premissa de que o discurso é elaborado em função do interlocutor. Então, uma das prioridades do orador é estabelecer um contato com o público e isso só será possível conhecendo para quem se fala. As características levantadas vão indicar quais os assuntos que o orador pode e deve abordar, bem como os que seriam desastrosos se utilizados no discurso. São estabelecidos, assim, acordos entre o orador e o auditório a respeito dos conceitos aceitos por ambos. A materialidade linguiística desses acordos é manifestada através das técnicas argumentativas. Esse processo tem como meta provocar reações no ouvinte.

Uma argumentação eficaz é a que consegue aumentar essa intensidade de adesão, de forma que se desencadeie nos ouvintes a ação pretendida (ação positiva ou abstenção) ou, pelo menos, crie neles uma disposição para a ação, que se manifestará no momento oportuno (Perelman y Olbrechts-Tyteca, 1996: 50).

Se essa proposição for tomada como ponto de partida, pode-se admitir que o discurso político, objeto de estudo neste trabalho, enfatiza a persuasão porque os argumentos são desenvolvidos com apelos emocionais voltados a obter ação imediata do auditório. "Para quem se preocupa com o resultado, persuadir é mais do que convencer, pois a convicção não passa da primeira fase que leva à ação" (Perelman y Olbrechts-Tyteca, 1996: 30).

Assim, o objetivo de todo orador é a conquista de um público ${ }^{2}$ que realize uma determinada ação. Portanto, a argumentação não tem motivo de existir sem um destinatário pois, quando se argumenta, quer-se modificar um estado existente. Ela se destina a influenciar uma pessoa ou um grupo para obter adesão às teses defendidas, o que, em alguns casos, significa realizar a ação proposta no discurso.

Perelman (1996) propõe pensar o auditório como conjuntos. Existiria um conjunto maior, o auditório universal, e outros contidos, os auditórios particulares. Há

\footnotetext{
${ }^{2}$ Sem nos atermos em discussões semânticas, apenas visando o uso de expressões utilizadas em comunicação social, aqui serão equivalentes a auditório, os termos público-alvo, público, interlocutor, destinatário.
} 
características comuns nesses grupos, mas também, particularidades, o que serve como ponto de referência para defini-los. De acordo com o mesmo autor, pode-se dizer que o auditório universal corresponde à humanidade como um todo, portanto, os argumentos que lhe são destinados valem para qualquer ser racional. O auditório é multifacetado, sendo assim, não é unânime. Por isso, no auditório universal inserem-se vários auditórios particulares, que dizem respeito a categorias com características em comum que os identificam. Eles correspondem a grupos que podem ser classificados em diversas variáveis como meio social, geográfico, etário e econômico a que pertencem. Existem então argumentos que podem ser relevantes para o conjunto da humanidade, enquanto outros, só atingem um grupo menor.

De uma forma mais simplificada, mas não menos subjetiva, o acordo proposto na Nova Retórica corresponde à primeira fase do esquema retórico de Aristóteles. Nesse momento, se buscam informações para fundamentar o discurso. É a busca por vínculos

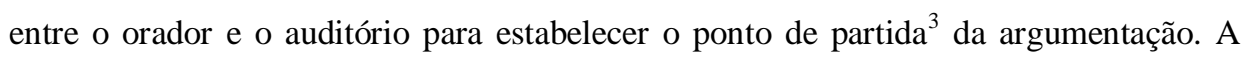
eficácia da argumentação depende dessas premissas, pois elas fazem com que o orador se adapte ao auditório com o auxílio de atitudes e conceitos. O raciocínio argumentativo, então, é desenvolvido a partir do que o orador supõe conhecer sobre seu auditório.

\begin{abstract}
"Cada meio poderia ser caracterizado por suas opiniões dominantes, por suas convicções indiscutidas, pelas premissas que aceita sem hesitar; tais concepções fazem parte de sua cultura e todo orador que quer persuadir um auditório particular tem de se adaptar a ele. Por isso a cultura de cada auditório transparece através dos discursos que lhe são destinados"
\end{abstract}

(Perelman, Olbrechts-Tyteca, 1996:23)

\footnotetext{
${ }^{3}$ Perelman utiliza esta expressão para reforçar a importância sobre o conhecimento dos valores que regem o auditório.
} 
Neste trabalho não se enfatizará esta categoria, entretanto, ressalta-se sua importância na delimitação dos conteúdos a serem proferidos pelo orador. As premissas, desta forma, podem ser classificadas em presunções (o que se presume sobre algo), fatos (acontecimentos conhecidos pelo público), verdades e valores (conceitos arraigados em determinado auditório).

Por sua vez, as técnicas se encarregam do encadeamento lingüístico dos argumentos. Elas se desenvolvem utilizando esquemas formais nos argumentos ${ }^{o_{-}}$ lógicos, enfatizando conhecimentos empíricos nos argumentos baseados na estrutura do real ou produzindo generalizações pelo caso particular. Como argumentos racionais, os autores propõem a classificação quase-lógica, que estrutura a linguagem aproximada do pensamento formal, isto é, baseada em raciocínios matemáticos ou de fundamento lógico. São os argumentos de contradição, identidade, tautologia, análise, reciprocidade, transitividade, inclusão da parte no todo, divisão do todo em partes, comparação, sacrifício e probabilidades. A proposta de implementar uma categoria de técnicas denominada argumentação fundada na razão, refere-se à demonstração, onde se encontram os argumentos que se baseiam em dados concretos como pesquisas, gráficos, ainda que suscetíveis à contestação. Acontece quando o orador prova sua tese e não apenas explora valores, conceitos e sentimentos baseados na subjetividade. A racionalidade é o elemento principal da superfície discursiva, quando são utilizados recursos aparentemente incontestáveis que referenciam a realidade.

Os argumentos baseados na estrutura do real, que correspondem ao uso da emoção, trazem as situações que fogem à demonstração porque não são estruturados em fórmulas matemáticas, mas em argumentos analógicos e apelam para as necessidades e valores essenciais humanos como amor, integridade, esperança. Perelman (1996) argumenta que como não há fórmula rígida para a estrutura dessa argumentação, o que importa é que os dados sejam fortes o suficiente para o desenvolvimento do discurso. Ele pondera que "o que nos interessa aqui não é uma descrição objetiva do real, mas a maneira pela qual se apresentam as opiniões a ele concernentes; podendo estas, aliás, 
ser tratadas, quer como fatos, quer como verdades, quer como presunções" (Perelman y Olbrechts-Tyteca, 1996: 298).

A argumentação fundada na estrutura do real é baseada em ligações de sucessão, de coexistência, simbólicas e hierárquicas, pois busca nos fatos empíricos a sustentação necessária para a defesa da tese. Observa-se que esses argumentos afetam o interlocutor justamente pelo fato de se aproximarem de sua realidade. "A vida cotidiana, familiar ou política, nos fornecerá, em profusão, exemplos de argumentação retórica" (Perelman, 1997: 87).

As experiências, condutas, acontecimentos, valores e juízos são o objeto dos argumentos baseados na emoção. São situações não provadas através de demonstração, mas que acordadas entre orador e público, possuem um grande poder argumentativo. Essas técnicas utilizam o conhecimento empírico do orador e do auditório para provocar a anuência. Perelman e Tyteca (1996) classificam diversos argumentos tão numerosos quanto às interpretações que as atitudes humanas possam trazer. Opta-se pela reflexão de duas linhas básicas: as ligações de sucessão e as de coexistência. No primeiro caso, os argumentos são baseados em relações entre os acontecimentos ou situações. É quando determinado fato é apresentado como decorrência de outro, sem necessariamente isto ser verdadeiro. No segundo caso, a argumentação é baseada na postura, atitudes ou história de vida do próprio orador.

A terceira categoria geral de técnicas argumentativas refere-se à argumentação pelo caso particular. São exemplos, modelos e antimodelos citados para ilustrar determinada situação e, na maioria dos casos, visar uma generalização.

Nota-se que o mesmo discurso pode incluir argumentos baseados na estrutura do real, os quase-lógicos e os fundamentados pelo caso particular. Aliás, os argumentos lógicos são pincelados com os baseados no conhecimento empírico, na vivência e sentimentos do público-alvo. 


\section{Considerações gerais sobre o discurso de Lula}

Este artigo baseia-se em pesquisa anterior realizada para o doutoramento na Universidade de São Paulo, defendido em 2005, sobre os discursos do Presidente Luiz Inácio Lula da Silva. Na ocasião, o foco do estudo estava relacionado ao posicionamento dele em relação à questão do emprego. Neste primeiro momento, pesquisou-se as falas de Lula desde o período de sindicalismo, nos anos 70 até o primeiro ano de mandato. Posteriormente, outras pesquisas foram realizadas, estendendo-se o prazo para os anos na presidência, bem como em suas campanhas eleitorais. Além do emprego, outro tema enfocado foi o Programa Bolsa Família e agora suas falas sobre a mulher.

Na tese, foi possível observar a mudança dos discursos em três fases: extremaesquerda (décadas de 70 e 80) fase de transição, detectada na década de 90 e o atual período de centro-esquerda, oficializado na campanha eleitoral de 2002.

O período classificado como extrema-esquerda durou pouco mais de 20 anos, desde o ingresso de Lula no sindicalismo até a primeira eleição presidencial, representando o Partido dos Trabalhadores (PT). O fato explica a imagem predominante de Lula no imaginário coletivo. Na ocasião, Lula, contestador, consagrou-se como uma liderança popular, abrindo a possibilidade de organização das massas. Em 1989, disputou o $2^{\circ}$ turno contra Fernando Collor, representando o pensamento da esquerda brasileira. Ele ainda mantinha características do perfil operário, tanto por sua postura ideológica, como pelo visual. Os aspectos remanescentes do período sindical correspondiam a um discurso coloquial e crítico, eliminando o diálogo com as classes dominantes e os acordos firmados com o Fundo Monetário Internacional. A crítica ao sistema político e econômico era claramente divulgado, como se pode observar no trecho a seguir, extraído do programa veiculado no Horário Eleitoral Gratuito ${ }^{4}$ :

\footnotetext{
${ }^{4}$ No Brasil, o Tribunal Superior Eleitoral disponibiliza aos partidos políticos espaço gratuito em rádio e televisão para a veiculação dos programas eleitorais no período que antecede as eleições.
} 
"Todo trabalhador sonha em poder comprar um presente de natal para o seu filho. (...) Esse é um sonho, esse é um sonho pequeno, esse é um sonho que não é nada pá (sic) quem trabalha a vida inteira. Pra quem trabalha 240 horas por mês. Esse é um sonho que não deveria ser nada pra quem trabalha de sol a sol. E por que não pode fazer isso? Por que não podem? Exatamente porque o sistema que predomina nesse país é um sistema capitalista arcaico, onde meia dúzia pode tudo e a maioria não pode nada".

(Lula, 08/10/1989)

Nas eleições de 1994, o PT considerava Lula vitorioso, devido à falência do governo Collor e à liderança do Partido no processo de impeachment ${ }^{5}$. Entretanto, em julho daquele ano, o então Ministro da Fazenda, Fernando Henrique Cardoso (PSDB), lançava o Plano Real. Com a moeda estabilizada, o país preferiu permanecer com FHC já no $1^{\text {o }}$ turno. A sua reeleição em 1998, foi fruto de articulações políticas com os governadores e o Congresso Nacional e Lula sequer chegou ao $2^{\circ}$. turno. Desde então, o Partido da Social Democracia Brasileira passou a representar o principal adversário nas urnas. Nessas duas eleições, o Partido dos Trabalhadores se disponibilizou para acordos com outros partidos de esquerda, ao contrário da primeira disputa.

No discurso do candidato petista, permaneciam traços discursivos, como as comparações e Lula começou a citar trechos de sua história, consolidando-o como símbolo de esperança de que se apossou. $\mathrm{O}$ conteúdo das falas ainda se referia às bases populares, entretanto, ganhou ênfase a política econômica do País, tema que nos períodos anteriores era tratado genericamente, ou com propostas que eliminariam, se aprovadas, o sistema vigente. Nesse contexto, houve uma reformulação da imagem do candidato, passando a apresentar um perfil mais conciliador, moderno e plural, conforme se observa neste trecho transcrito do programa veiculado no Horário Eleitoral Gratuito:

\footnotetext{
${ }^{5} \mathrm{O}$ então presidente Fernando Collor de Melo foi afastado do governo, na metade do mandato, devido a denúncias de corrupção. Várias entidades participaram do processo, que gerou mobilização popular.
} 
“Antes de começar essa campanha, eu resolvi viajar pelo Brasil. Percorri 40 mil quilômetros, de trem, de ônibus e de barco. Conversei com pequenos, médios e grandes empresários. Conversei com sindicalistas. Conversei com índios. Conversei com pescadores. (...) Eu conversei com toda a sociedade brasileira para ganhar subsídios para construir um programa de governo. Um programa de governo não como uma peça de laboratório, mas um programa de governo olhando nos olhos das pessoas, no coração das pessoas. (...) Nessa viagem eu aprendi que o povo brasileiro está precisando apenas de uma oportunidade. Uma oportunidade de trabalhar. Uma oportunidade de produzir. Uma oportunidade de conquistar a cidadania”.

(Lula, 1994)

O discurso mais amplo é constatado pela variedade de públicos citados e por expressões como "conversei" e "aprendi", indicando ponderação. Há uma tentativa de sensibilização com a explanação da viagem pelo país buscando provar o conhecimento do então candidato pelas causas populares brasileiras. A questão do emprego é apresentada como uma ferramenta de conquista para o que Lula chamava de cidadania.

A consagração da lógica que está regendo o governo Lula manifestou-se em junho de 2002, com a publicação da Carta ao Povo Brasileiro. O documento apresentou as diretrizes que seriam adotadas no caso da vitória petista, especialmente em relação às medidas econômicas. A campanha vitoriosa mostrou um candidato ponderado e estadista. O slogan "a esperança venceu o medo" reforçou o caráter simbólico de Lula, que se colocava como a esperança do País. A adesão de um novo público à sua candidatura explica-se, entre outros fatores, por sua postura de rompimento com os velhos dogmas do PT, sua mudança em relação às propostas econômicas e à vicepresidência preenchida por um partido de direita, o Partido Liberal (PL).

Durante todo o período analisado, a argumentação, aliada à fundamentação em valores universais, enalteceu as qualidades do trabalhador brasileiro. Enfatizaram-se as características, "competência, inteligência, amabilidade e disposição”. Algumas vezes, 
ressaltaram-se alguns aspectos para provar a tese de que os assalariados poderiam engajar-se em uma luta por melhores condições de vida, como nas fases de sindicalismo à campanha de 1998. Na terceira fase, a partir de 2002, a qualificação do operário foi apresentada como uma vantagem para os investidores estrangeiros e como forma de avalizar as propostas governamentais.

Os argumentos foram se alterando à medida que o contexto sócio-político exigia novas posturas de Lula. A alteração mais evidente refere-se à concepção ideológica que passou de uma esquerda contestadora e marxista, para uma tendência centro-esquerda, conciliando a importância da economia de mercado e às práticas a favor da igualdade social. A estrutura argumentativa, entretanto, demonstrou mais permanência do que mudança porque os traços argumentativos continuaram nos discursos no decorrer desses 30 anos, enquadrando-se na fundamentação em valores universais como "justiça, liberdade, igualdade, generosidade e responsabilidade". O carisma dos discursos de Lula pode ser explicado pelo uso de vocativos, comparações e simbolismo. As técnicas que predominaram foram as relações de causalidade, argumento de autoridade, pelo exemplo, direção, incompatibilidade e coexistência entre ato e pessoa.

Contudo, a mudança, em especial a partir da campanha de 2002, não significou descaso com o problema, porém apresentou novas formas de resolvê-lo. Nesse momento se observa a mutação, pois nos discursos precedentes, durante o sindicalismo e o início do PT, a solução viria pela dissolução do sistema vigente e a implementação de uma nova estrutura política e econômica. Com o passar do tempo, depois da segunda derrota na campanha eleitoral à Presidência, houve adesão à ordem social vigente, apontando para o continuísmo e apresentando propostas conciliatórias com o poder dominante. Entre esses acordos estão a execução das Reformas, a manutenção dos contratos internacionais e a captação de capital privado.

Com as pesquisas realizadas no decorrer de oito anos, pode-se afirmar que os discursos de Lula possuem pontos em comum em relação às técnicas adotadas. $\mathrm{O}$ carisma natural do Presidente converge para a utilização da argumentação baseada na estrutura do real, em especial nas ligações de coexistência. Isto significa que ele usa, na 
maioria dos pronunciamentos, trechos da história pessoal para gerar identificação e aproximação com o público. Em geral, relata situações que demonstrem superação de dificuldades imprimindo um tom eloqüente em sua fala.

Outra característica permanente é o uso de comparações, metáforas e analogias. Existe um uso quase didático desses recursos quando se trata de um público mais popular. Aliado a isto, encontram-se termos da oralidade, excesso de informalidade e gírias, cuja significação pode ser considerada dúbia. Entretanto, tal recurso já causou constrangimentos e foram consideradas gafes, inclusive em território internacional. Lula também faz uso de valores universais e senso comum para apoiar sua argumentação. Também cita freqüentemente exemplos para promover generalizações.

Os argumentos quase-lógicos são estratégias adotadas em dois momentos: primeiro quando há necessidade de comprovar os avanços do governo e, segundo, quando medidas antipopulares precisam ser tomadas.

Com base nas informações precedentes, tanto do aparato teórico de análise, bem como a contextualização das características predominantes nos discursos de Luiz Inácio, parte-se para a análise do corpus proposto.

\section{Metodologia de análise}

Para este estudo, realizou-se pesquisa exploratória para delimitação do corpus. Desta forma, dez pronunciamentos oficiais ${ }^{6}$ foram selecionados tomando como critério, em primeiro lugar, as falas em comemoração ao Dia Internacional da Mulher, realizadas anualmente e somam oito discursos. Assinala-se que em 2004, o Presidente fez dois discursos na data, ambos relacionados à temática. Os outros dois, foram selecionados devido à relevância em relação ao tema "mulher". São eles: em agosto de 2003, durante a posse do Conselho Nacional dos Direitos das Mulheres e lançamento do Programa de

\footnotetext{
${ }^{6}$ Todos os pronunciamentos estão disponíveis na íntegra em www.planalto.gov.br
} 
Combate à Violência Contra a Mulher; e em agosto de 2006, na cerimônia de sanção da Lei de Enfrentamento à Violência Doméstica.

Após a seleção dos discursos, realizou-se uma análise da estrutura argumentativa, tomando como parâmetro o esquema proposto por Perelman (1996), enfatizando as técnicas utilizadas.

\section{Resultados da análise}

O discurso constrói-se tendo em vista o público ao qual a mensagem é destinada, o papel social de quem fala, o conteúdo e o contexto. Em relação ao público, os discursos proferidos por Lula no Dia da Mulher assemelham-se em termos gerais por serem destinados ao público feminino e às autoridades políticas, mas diferenciam-se de acordo com o contexto. Dos discursos analisados, sete foram proferidos no Palácio do Planalto, sede do governo federal, e apenas três em locais distintos, cada um deles em uma região brasileira (sul, nordeste e sudeste).

Em 2003, primeiro ano de governo, Lula participou de uma cerimônia oficial no Palácio do Planalto e iniciou sua fala citando a vida pessoal para contextualizar o problema cultural relacionado às questões de gênero. Apesar de a situação estar relacionada diretamente ao orador, o argumento adotado é classificado, de acordo com Perelman (1996) como argumentação pelo caso particular, pois é a citação de fatos específicos para promover uma exemplificação.

“E, como a diretoria era só de homens, nós não tínhamos uma mulher metalúrgica para colocar na mesa. Eu sei que essa guerra entre "coloca uma mulher na mesa ou não", tomou a primeira manhã do congresso. Até que os homens, sendo maioria, decidiram não colocar mulher na mesa mesmo, e não colocamos a mulher na mesa. 
Passados 25 anos, ontem eu participei do Encontro dos Prefeitos do Brasil e tinha por volta de 1.800 Prefeitos e Prefeitas. Havia muitas Prefeitas. E, de repente, quando se forma a mesa, eu me dei conta, quando chamado para falar, de que não havia uma única mulher na mesa".

(Lula, 12/03/2003)

Observa-se no trecho, a não representatividade feminina em atos políticos, primeiro em um congresso de metalúrgicos na década de 70, depois no Encontro de Prefeitos Brasileiros, em 2003. Em ambos os casos, além de a mulher atuar em papéis secundários, como observadoras, tem-se a hegemonia masculina e a disputa entre os gêneros. O conflito é ilustrado, principalmente, pelo uso da expressão "guerra".

Outros trechos de relevância demonstram o embate entre o papel da mulher considerada "atual" e o perfil traçado em diversos momentos nos discursos analisados, como a mulher protetora, aliada necessariamente à maternidade. Apesar de os discursos enfatizarem a palavra-chave "conquista" sempre há limites para tal e o estereótipo da mulher que cuida da casa e dos filhos permanece, conforme o exemplo abaixo.

"Eu duvido de que uma mulher venderia a sua casa por conta de alguns centavos, porque não tem nada mais sagrado para uma dona de casa, não tem nada mais sagrado para uma mulher do que um ninho, onde ela vai cuidar dos seus filhos".

(Lula, 12/03/2003)

Está explícito neste trecho, o apelo emocional com o uso da comparação nas expressões "ninho" e o "sagrado". Relacionado ao elogio de a mulher ser mais responsável, está a função social de mãe e dona do lar.

No conteúdo abaixo, o Presidente reflete os acordos estabelecidos com seu público alvo, tanto homens quanto mulheres. Isso porque os discursos remetem às 
conquistas das mulheres no decorrer do tempo, mas criam a salvaguarda masculina associada às questões culturais que promoveriam a não mudança de comportamento.

"E na questão da mulher nós temos uma outra coisa grave, que é a nossa formação cultural. Nós, os homens, temos problemas a serem enfrentados e vencidos. Eu brinco muito, eu conheço companheiros meus, militantes há muitos anos, que viraram "primeiros-damos". Não é fácil, ele não agüenta o sucesso da mulher. A mulher chegar mais tarde, à noite, a mulher fazer as reuniões que ele faria se fosse ele o prefeito, ele não gosta. E isso nós temos dentro da nossa casa, no cotidiano. Todo mundo fala da boca para fora, é fácil falar. A coisa mais simples é fazer um discurso, mas para qualquer marido moderno, se a mulher chegar três dias por semana depois dele em casa é motivo de briga, porque ele está acostumado a chegar depois".

(Lula, 09/03/2009)

Essa questão cultural, presente em todos os discursos analisados, serve para estabelecer acordos com os auditórios particulares, separados aqui por gênero. Enquanto as mulheres desejam igualdade, os homens permanecem acomodados com a adoção do discurso de que é difícil alterar uma cultura de séculos. A técnica argumentativa adotada chama-se "vínculo causal" na qual procura-se relacionar fatos e justificá-los por meio de ações e suas respectivas conseqüências. Isto significa que, se não houver mudança no cenário brasileiro sobre as questões de gênero, o governo teria feito sua parte, mas não conseguiria alterar rapidamente um contexto de hábitos existentes previamente.

No trecho a seguir, observa-se mais uma forma de espelhamento da realidade.

"A realidade da mulher brasileira mudou muito nas últimas décadas. Engana-se bastante, por exemplo, quem ainda pensa que ela se vê como uma dona de casa, conformada e satisfeita com a sua dependência econômica e submissão ao marido, ou pensa que ela, simplesmente, dedica a sua vida à espera de um 
príncipe encantado. Não é assim que as mulheres brasileiras se vêem. Não é assim que as mulheres brasileiras agem.

Engana-se, também, quem pensa somente na mulher como trabalhadora remunerada. Ela já está no mercado de trabalho ou busca entrar nele. Mas a maioria das brasileiras acumula o trabalho fora, remunerado, ao trabalho doméstico, não pago".

(Lula, 12/03/2003)

O retrato da mulher brasileira sofre, neste discurso, um lapso temporal indicado por "quem ainda pensa que ela se vê como uma dona de casa" ou "ela já está no mercado de trabalho". Se o inicio da inserção da mulher no mercado for considerado, tem-se o século XX como referência. Por outro lado, há a afirmação de ela permanecer com o trabalho doméstico. Semelhante proposição encontra-se na fala proferida seis anos depois, e se ressalta as últimas frases nas quais o posicionamento do orador está indicado.

"Hoje mais de 50\% dos lares brasileiros são dirigidos por mulheres. Então, hoje acabou aquele negócio de dizer: “a mulher trabalha? Não!”. É o maior cinismo cultural do mundo. Uma mulher fica em casa, às vezes, cuidando de cinco filhos, e perguntam assim: "A sua mulher trabalha? Não". Não tem tabu e preconceito maior do que esse. Possivelmente, o fato de ela ter ficado em casa significa muito mais trabalho do [para] quem saiu de casa. Por que muitas meninas preferem trabalhar em uma fábrica, que a gente acha penoso, e não trabalhar [como] empregada doméstica? É porque o trabalho doméstico, se fosse bom, era o homem que faria. Se fosse prazeroso, era o homem que faria". (Lula, 09/03/2009. Grifo nosso)

Constata-se o uso do argumento de transitividade no qual se transfere valores a elementos distintos, em especial no trecho grifado. O raciocínio procura mostrar que o 
homem apenas fica com as "coisas boas" e a mulher, pelas características culturais citadas, encarregam-se do que se considera ser algo que não gera satisfação pessoal.

No primeiro ano de governo, o perfil da mulher independente que trabalha e não espera um marido está exposto para respaldar uma proposta governamental, alicerçada pelo argumento de direção, ou seja, o que pretende ser feito.

“O nosso Governo vai enfrentar para valer essa situação. A primeira medida foi a de dar status de Ministério à Secretaria Especial de Políticas para as Mulheres. São elas que devem ser as protagonistas desse novo momento político do nosso país". (Lula, 12/03/2003)

Este trecho apresenta a criação de um ministério, como se já houvesse sido estabelecido e de que as mulheres deveriam atuar politicamente. Entretanto, traz três contradições em relação aos discursos posteriores. A primeira refere-se à transformação da Secretaria Especial. Em março de 2009, Lula repete o mesmo conteúdo, mas em tom de promessa, o que se configura como argumento de direção. Seis anos antes, a mesma proposição aparece como um fato consumado.

"Eu acho que para você ${ }^{7}$ ficar menos dependente da Dilma ${ }^{8}$, nós vamos mandar também transformar a Secretaria Especial [de Políticas para as] Mulheres em Ministério, porque parece que não, mas o fato de transformar em Ministério, a liberdade orçamentária ajuda muito na elaboração e na execução das políticas públicas. Depois, se um dia alguém achar que Ministério é demais e quiser acabar, que ouse".

(Lula, 09/03/2009)

\footnotetext{
${ }^{7}$ Nilcéia Freira, responsável pela Secretaria Especial de Políticas para as Mulheres.

${ }^{8}$ Dilma Roussef, Ministra da Casa Civil, e indicada por Lula como sua candidata na eleição de 2010.
} 
Fica evidente que a Secretaria não se tornou um Ministério em 2003, nem em 2009, e que isto ainda é uma promessa. Ressalta-se, também, que a última frase blinda o Presidente de críticas posteriores de seus adversários, bem como demonstra força junto ao público-alvo.

A segunda contradição refere-se ao fato de em 2003, Lula apoiar a participação política feminina, tendo em vista também os dois exemplos de exclusão que citou no inicio daquele discurso. "São elas que devem ser as protagonistas desse novo momento político do nosso país”(Lula, 12/03/2003). Nos anos posteriores, viu-se uma afirmação completamente diferente, mesmo sendo proferida em tom de humor.

“Hoje, as mulheres dirigem grande parte dos movimentos sindicais neste país. As mulheres estão nos partidos políticos, estão no poder judiciário, estão governando prefeituras, estão governando estados. Eu espero que pare por aí, que não queiram muito mais do que isso".

(Lula, 08/03/2004)

A técnica argumentativa utilizada é a divisão do todo em partes, presente na categoria dos argumentos quase-lógicos. O conjunto total de mulheres brasileiras divide-se em subcategorias de acordo com a classe de liderança política. Tanto no exemplo acima, como abaixo, observa-se a mesma situação. Primeiro a mulher é enaltecida por suas conquistas e restringe até onde se pode conquistar.

"Por último meus companheiros, eu quero dizer às mulheres brasileiras que vocês já são maioria na população brasileira, já são 52\%, vocês já têm cargo de vereadora, de prefeita, de governadora, eu espero que vocês não sejam desaforadas e não comecem a pensar logo na Presidência da República, não. Eu espero que vocês vão devagar com essa pressa de poder”. (Lula, 08/03/2005. grifo nosso) 
No trecho grifado, fica evidente o tom de descontração do discurso, em especial pela expressão "desaforadas", considerando-se, inclusive, que o pronunciamento foi realizado em um evento popular no nordeste do Brasil. Entretanto, indica que, apesar do longo período em busca da igualdade de deveres e de direitos, a mulher teria que aguardar mais tempo para estar apta à Presidência da República.

Ainda em 2008, tal restrição à participação política feminina permanece, conforme exemplo abaixo.

“E é precisamente o enorme respaldo obtido na II Conferência que, com certeza, levará ao sucesso também do II Plano Nacional de Políticas para as Mulheres. Este novo Plano representa uma extraordinária união de esforços do Governo Federal para fazer avançar as políticas para as mulheres. Como disse a nossa companheira Nilcéa, são 394 ações distribuídas em 11 áreas estratégicas - entre as quais seis novas - definidas na II Conferência Nacional. São elas: participação das mulheres nos espaços de poder e decisão espero que não com muita pressa, vocês vão devagar, porque senão vocês vão criar um outro segmento da sociedade chorando, reclamando; desenvolvimento sustentável no meio rural, na cidade e na floresta, com garantia de justiça ambiental, soberania e segurança alimentar; direito à terra, moradia digna e infra-estrutura social nos meios rural e urbano, considerando as comunidades tradicionais; cultura, comunicação e mídia igualitárias, democráticas e não discriminatórias; enfrentamento do racismo, sexismo e lesbofobia; enfrentamento das desigualdades geracionais que atingem as mulheres, em especial atenção às jovens e idosas".

(Lula, 05/03/2008. Grifo nosso)

Ao mesmo tempo em que pede, novamente, para as mulheres conquistarem o espaço na política com mais calma, expõe o lado emotivo feminino de forma pejorativa, conforme o trecho acima grifado: "criar um outro segmento da sociedade chorando, 
reclamando". O conjunto dos discursos é contraditório, pois, por um lado, faz afirmações positivas como a competência da mulher, defende projetos e por outro, a mantém em um papel estreitamente vinculado a um suposto marido, cuja conquista política não viria por mérito, mas por "chorar e reclamar".

Justamente em relação a isso, reside a terceira contradição. Em 2008 iniciaram os rumores sobre a indicação da Ministra Chefe da Casa Civil, Dilma Roussef, como candidata do PT na eleição de 2010 e em 2009, Lula assumiu a pré-candidatura dela9 . Se antes ele freava a participação feminina, depois passou a estimular e também a expor Dilma Roussef em eventos do governo federal.

Como foi dito anteriormente nas considerações gerais sobre o discurso de Lula, ele se apropria da técnica argumentativa "pessoa e seus atos" como uma constante. Ou seja, relata trechos de sua história pessoal a fim de gerar proximidade com o público. $\mathrm{Na}$ questão da mulher não poderia ser diferente, e o Presidente citou na maior parte dos discursos, a relação com as mulheres mais importantes de sua vida: em primeiro lugar sua mãe e em segundo, a esposa. Em dois discursos, também, citou a presença das trabalhadoras da época do sindicalismo.

"Eu sou filho de uma mulher que nasceu analfabeta, teve 12 filhos - quatro morreram antes de completar 30 dias de vida -, morreu analfabeta, mas na primeira tentativa de violência contra ela - feita pelo seu marido -, ela simplesmente rompeu com ele, foi viver sozinha com oito filhos e provou que quando a mulher tem garra, determinação, ela não tem que ficar

\footnotetext{
9 "Ela é a minha candidata, mas eu não sou o partido [o PT]" (Lula, 27/04/2009) Disponível em http://www1.folha.uol.com.br/folha/brasil/ult96u558074.shtml.

$\mathrm{Na}$ referida semana, inclusive, a Ministra revelou estar com câncer e iniciou tratamento de quimioterapia. O fato não alterou a pré-candidatura e repercutiu na imprensa nacional. A Veja, revista semanal de maior circulação no Brasil, ofereceu na primeira edição de maio/2009, ed. 2111, a seguinte manchete: "A candidata e o câncer. A vergonhosa politização do drama pessoal da Ministra". E ainda na versão on line "O governo tenta transformar um assunto grave e delicado, a doença da ministra Dilma Rousseff, em trunfo para a campanha presidencial do próximo ano" Disponível em http://veja.abril.com.br/newsletter/newsletter.html.
} 
dependendo de uma pessoa que às vezes ao invés de ajudar, atrapalha". (Lula, 08/03/2004)

Além de a argumentação ser baseada na vida do Presidente, constata-se a fundamentação pelo caso particular pelo exemplo que a mãe dele se torna também para outras mulheres. Isto fica explícito na última frase quando cita que às vezes estar junto com alguém atrapalha e não ajuda. Na verdade, foi um raro momento que desvincula a imagem da mulher ao marido, mas não a separa do estereótipo da figura materna. Abaixo, a maternidade é ressaltada também em relação à primeira dama, Marisa.

"E eu pedi para a Marisa vir aqui, porque eu devo parte do que eu sou na vida à minha mãe, uma nordestina de Garanhuns que teve a coragem de colocar oito filhos num "pau-de-arara" e sobreviver em São Paulo, pensando que ia encontrar o maridão que já estava lá desde 1945, isso foi em 1952, e quando ela chegou para se encontrar com o maridão dela, ele estava casado com outra. E ela não perdeu a ternura e cuidou dos oito filhos sozinha e conseguiu até fazer com que um deles chegasse à Presidência da República. Uma outra é esta "galega" ${ }^{10}$ " que está aqui do meu lado. Esta "galega", eu não sei se ela teve a sorte de me encontrar ou eu tive a sorte de encontrá-la. O dado concreto é que nós vamos fazer 31 anos de casados e nesses 31 anos nós já passamos por momentos muito difíceis. De vez em quando eu digo que a Marisa foi a mãe e o pai dos meus filhos. Primeiro, pela minha atividade sindical, eu não estava junto com ela em nenhum momento em que nasceram os meus filhos. Depois, eu nunca estava em casa para ver o boletim da molecada, para ver se estava tudo bem na escola ou se não estava bem. (...) $\mathrm{E}$ mais ainda, mesmo quando eu fui preso em 1980, a Dona Marisa, que parecia ser frágil, que parecia ser debilitada para enfrentar uma situação daquelas, em

\footnotetext{
${ }^{10}$ Expressão popular que designa mulheres loiras e de pele clara.
} 
nenhum momento ela vacilou em assumir, junto com as mulheres de São Bernardo do Campo, a luta que os metalúrgicos estavam fazendo". (Lula, 08/03/2005)

Todo o relato gera a sensação de proximidade entre o público e o orador através da exposição da vida pessoal do Presidente, que enfatiza a força dessas mulheres. Como argumentação fundamentada pelo caso particular, visa promover uma generalização enaltecendo características femininas. No caso especifico, gera empatia por aparentar a valorização das qualidades relacionadas à maternidade e na explicação de que se ele chegou à Presidência foi devido à presença das duas figuras na vida dele. Por fim, retoma a vinculação com a presença do homem no papel de marido, atrelada à demonstração de habilidades de Dona Marisa, antes não citadas, como a mobilização intelectual e política, durante o movimento sindical.

Merece, ainda, destaque a análise dos discursos sobre as medidas para o combate à violência, apesar de não serem proferidos no dia da Mulher. Durante a posse da diretoria do Conselho Nacional dos Direitos das Mulheres, em 2003, o presidente enfatizou um aspecto presente em todos os outros discursos: a necessidade de educação para as questões de gênero como solução para o problema cultural sobre o tema.

"E a educação da proteção da mulher, da igualdade, da cidadania, que a mulher tanto precisa, acho que tem que ser dada numa sala de aula em que meninos e meninas possam ouvir, porque não adianta apenas uma parte ouvir. É preciso que as duas partes ouçam, para que possamos apostar que os nossos filhos e os nossos netos viverão em uma nação infinitamente mais tranqüila na relação entre a mulher e o homem, do que vivemos hoje". (Lula, 27/08/2003)

A técnica argumentativa utilizada é o argumento de fins e meios, no qual aponta-se um objetivo e a forma de atingi-lo. Aqui Lula argumenta que para se alcançar 
a igualdade entre os gêneros, o caminho a ser percorrido envolve a educação das gerações atuais.

Em 2006, o pronunciamento no Dia das Mulheres se tornou um discurso eleitoral, no qual apenas falou-se sobre os programas sociais do governo, nem todos relacionados às questões femininas. E, talvez, por justamente ser um ano de eleições, em agosto houve a sanção da Lei de enfrentamento contra a violência doméstica e familiar, chamada de Lei Maria da Penha.

"Esta Lei representa, na verdade, uma baliza para corrigir o desequilíbrio de poder que existe entre homens e mulheres em nossa sociedade. Como acontece em qualquer outro desequilíbrio de poder, esse também alimenta a injustiça, gera opressão e sustenta a desigualdade. Infelizmente, essa desigualdade ainda é o quadro predominante nas relações de gênero em nosso tempo, e não apenas em nossa sociedade. No mercado de trabalho, por exemplo, a mulher ainda ganha, em média, menos que o homem, embora exerça funções iguais com desempenho equivalente e, não raro, superior ao dele. Todavia, é na violência doméstica que a expressão mais perversa dessa desigualdade se expressa e o faz de forma oculta, protegida atrás das paredes e naturalizada sob camadas seculares de cultura machista. É isso que a Lei de Enfrentamento à Violência Doméstica e Familiar contra a Mulher vem corrigir.".

(Lula, 07/08/2006)

O discurso presidencial utiliza a técnica argumentativa de identidade, através das afirmações conhecidas pela mulher: sofrer com discriminação no mercado de trabalho e com violência em casa. Ao reafirmar a existência da "cultura machista", Lula certifica-se de estar refletindo o que Perelman (1996) denomina de "verdade", ou seja, valores e conceitos enraizados em determinado grupo social. Com isso, o presidente tende a conquistar a confiança de suas eleitoras a partir do momento que expressa suposto conhecimento de causa. 
A aprovação dessa lei foi amplamente citada posteriormente. No exemplo abaixo, Lula faz uma forte crítica ao comportamento masculino para respaldar a força da lei aprovada.

"Portanto, é preciso mais que uma lei, é preciso que haja uma evolução na qualidade da massa encefálica que temos dentro do cérebro para compreender a importância da convivência paritária, igual, entre homens e mulheres, porque a violência contra a mulher é proibida por lei. No ano passado aprovamos a Lei Maria da Penha, que dá cadeia e não cesta básica para quem bater na mulher”. (Lula, 07/03/2007. Rio de Janeiro)

Em 2008, durante a comemoração antecipada do Dia da Mulher, um longo discurso retomou as ações efetivadas pelo Governo em prol da igualdade de gênero.

“Também, nós fizemos o Plano Nacional de Enfrentamento ao Tráfico de Pessoas; o Plano Integrado de Enfrentamento à Feminização do HIV/Aids e outras Doenças Sexualmente Transmissíveis; a Política Nacional de Planejamento, que nós anunciamos em São Paulo; a Central de Atendimento à Mulher - Ligue 180, que já teve mais de 200 mil atendimentos no ano passado; os Programas Mulher e Ciência e Gênero e Diversidade na Escola; o programa Pró-Eqüidade de Gênero, tudo isso, nós já colocamos em prática e vai andando na medida em que vai havendo a evolução da sociedade e a compreensão do que isso significa”.

(Lula, 05/03/2008)

A relação dos programas procura demonstrar o papel governamental como um retorno à sociedade ou às lideranças. Contudo, pela construção argumentativa e exposição da última frase, percebe-se que Lula divide a responsabilidade pelo sucesso com o conjunto da população brasileira. Esse raciocínio é reforçado por outros trechos, como o citado abaixo. 
“Quem lê a Constituição brasileira em qualquer lugar do mundo vai falar: este país é o país mais extraordinário do planeta. Agora, entre a Constituição e a prática tem uma diferença de séculos, que é o resultado da tradição, da subordinação a que a mulher foi submetida durante séculos e séculos como cidadã de segunda classe".

(Lula, 05/03/2008)

O Presidente retoma as questões culturais para no decorrer de sua fala argumentar a favor das ações desenvolvidas pelo governo e cobrar a aplicação da Lei Maria da Penha.

"Acho que uma das conquistas mais simbólicas que nós tivemos foi a promulgação, aprovação e promulgação da Lei Maria da Penha. Quem participou da campanha de 2006, viu quantas vezes eu fiz discursos sobre a questão da Lei Maria da Penha. Às vezes, eu ficava receoso de que os homens que estavam ali não iriam querer voltar mais, porque... mas a reação das mulheres era uma coisa excepcional. Havia efetivamente a compreensão de que as mulheres tinham conquistado uma coisa extraordinária, porque nós sabemos que no submundo da violência nem toda ela é avisada, é descrita e é denunciada. Tem muita gente no Brasil que ainda apanha em silêncio. E nós não podemos concordar com isso".

(Lula, 05/03/2008)

Observa-se que o discurso pela defesa da integridade da mulher está muito relacionada com a violência física, talvez a mais evidente. Em relação às outras formas, não há registro, apenas a citação do preconceito e discriminação no mercado de trabalho. No último pronunciamento analisado, realizado em março deste ano, reforçase a forma mais comum de violência contra a mulher e o papel da educação como agente transformador. 
“Eu me lembro da repercussão da aprovação da Lei Maria da Penha. Eu me lembro de quantos discursos, Nilcéa, eu fiz por este país afora, chamando nós, os homens, à responsabilidade sobre o que nos esperava se nós ousássemos agredir a nossa companheira. E eu lembro que a lei hoje é conhecida de muita gente neste país. Obviamente que a lei, por si só, não vai resolver todos os problemas, porque tem uma questão cultural, tem uma questão de medo ainda, tem uma questão, às vezes, de falta de proteção ou de garantia, muitas vezes, as pessoas têm medo de denunciar, tem um medo ainda. Mas esse é um processo em que a gente vai avançando, não adianta achar que porque tem a lei vai ser tudo resolvido amanhã. Não vai. A lei vai sendo executada corretamente na medida em que as pessoas vão tendo consciência de que podem se valer daquele instrumento jurídico para se autodefender".

(Lula, 09/03/2009)

O grande mote governamental na questão do combate à violência física contra a mulher encontra-se, portanto, na reafirmação do papel da lei criada em 2006.

O conceito de cidadania vinculado à mulher centrou-se no público das trabalhadoras rurais e a criação de crédito agrícola especialmente destinado a elas, bem como programas de incentivo à regularização da documentação pessoal. 


\section{Considerações finais}

Procurou-se, neste trabalho, analisar os discursos do Presidente do Brasil, Luiz Inácio Lula da Silva, durante as comemorações no Dia Internacional da Mulher, no decorrer de seus dois mandatos, para verificar quais os temas relacionados e o perfil da mulher exposto nas falas.

Com o corpus de dez pronunciamentos analisados, verificou-se que, apesar da variação temporal, as falas presidenciais apresentam eixos em comum durante os dois mandatos: citam as mulheres importantes na vida do presidente, tratam da violência doméstica, enfatizam a expressão "conquista", relacionam a mulher com o papel de mãe e esposa e criticam as questões culturais que impedem uma mudança de atitude em relação ao tratamento discriminatório em função das diferenças de gênero.

As temáticas foram centradas para os públicos de mulheres trabalhadoras rurais, mulheres vítimas de violência e mulheres engajadas politicamente nos movimentos sociais. O auditório universal também foi contemplado, principalmente, no que se refere à inserção da mulher no mercado de trabalho.

O perfil da mulher variou entre a mãe, dona de casa com a mulher que está inserida em um processo político de igualdade de gênero. Os discursos apresentaram contradições neste âmbito, pois os avanços assinalados teriam um limite de espaço, em especial, relacionado às questões políticas. E, em nenhum momento, a mulher esteve desvinculada à sua função de mãe e dona de casa. Quanto ao papel de esposa, houve dois enfoques: o primeiro atribuindo à mulher um papel secundário, como apoiadora do homem; o segundo exemplificado pelo relato pessoal sobre a mãe do presidente e pela descrição que a mulher brasileira não espera um "príncipe encantado", indica que, na visão de Lula, a mulher poderia atuar como protagonista da própria história.

A técnica argumentativa mais adotada foi a argumentação pelo caso particular com a citação de exemplos para promover generalizações e identificação com o público alvo. Os valores ressaltados se concentraram em simbolismos da figura materna e no conceito da palavra "conquista". 
Durante todo o período, o Presidente ressaltou a importância da educação para alterar o pensamento machista enraizado na sociedade brasileira. A cultura é considerada um problema que impediria a solução dos embates entre homens e mulheres nos diversos âmbitos que abrangem as questões de gênero. Ela seria a própria proteção do governo caso os programas implementados não surtissem o efeito desejado ou visível a um curto espaço de tempo.

No primeiro mandato (2003-2006), o perfil da mulher esteve mais restrito ao seu papel como mãe e lutando por inserção igualitária na sociedade. Nos discursos, a participação política aceita se limitava aos movimentos sociais, sindicatos e governos municipais e estaduais, com explícita restrição sobre um poder maior, como a Presidência da República. Os discursos procuravam mostrar o que o governo federal faria para mudar as situações de conflito.

Já no segundo mandato (2007-2010) observou-se até o momento desta análise, uma ligeira mudança na linha ideológica do discurso. As falas procuraram demonstrar as conquistas realizadas até o momento pelas ações governamentais e enfatizaram a importância da transformação do pensamento vigente em relação à competência política feminina. Este fato talvez se relacione com a pré candidatura anunciada da Ministra Chefe da Casa Civil, Dilma Roussef, à Presidência da República. Como o sucessor escolhido por Lula é uma mulher, muito do que foi restringido quanto ao poder político feminino, teve e terá ainda nos próximos meses, antes das eleições de outubro de 2010, de ser alterado nos pronunciamentos presidenciais. Entretanto, como ressalta Ducrot (1972), para o dito não existe o não dito, resta que a memória dos brasileiros e das brasileiras esteja em atividade para lembrar o posicionamento apresentado até então pelo Presidente Lula e cobre uma efetiva mudança também por parte dele para aceitar e estimular a presença política da mulher sem qualquer limitação. 


\section{BIBLIOGRAFIA}

- Aristóteles. (s/d) A arte retórica e a arte poética. Trad. Antônio Pinto de Carvalho. Rio de Janeiro: Ediouro.

- Aristóteles. (2001) Política. (texto integral). São Paulo: Martin Claret.

- Aristóteles. (2003) Retóricas das Paixões. São Paulo: Martins Fontes.

- Ducrot, Oswald (1972) Princípios de semântica lingüística (dizer e não dizer). São Paulo: Cultrix.

- Foucault, Michel (1979) Microfísica do poder. 16 ${ }^{\mathrm{a}}$. ed (2001). Rio de Janeiro: Graal. . (1996) A ordem do discurso. $2^{\text {a }}$ ed. São Paulo: Loyola.

- Lula - o presidente - trajetória de um vencedor. (2002) DVD Brasil. Produção Rádio e Televisão Bandeirantes ltda.

- Panke, Luciana. (2005) As mudanças de argumentos nos discursos de Lula, sob o prisma da temática emprego. Tese defendida na Escola de Comunicações e Artes da Universidade de São Paulo, 345pgs.

___. (2007) A questão "emprego" no discurso político do Presidente do Brasil durante a campanha para reeleição. Trabalho apresentado durante o $7^{\circ}$. Sopcom, Braga, Portugal.

- Pêcheux, M. (1969) Analyse automatique du discours. Paris: Dunod.

- Perelman, Chaim. (1997) Retóricas. São Paulo: Martins Fontes.

- Perelman, Chaim. Olbrechts-Tyteca, Lucie. (1996) Tratado da argumentação - nova retórica. São Paulo: Martins Fontes.

- Plantin, Christian. (1990) Essais sur l'argumentation. Paris: Kimé.

- Reboul, Olivier. (2000) Introdução à retórica. 2ed. São Paulo: Martins Fontes.

- Silva, Luiz Inácio Lula. Pronunciamentos oficiais. Disponível em www.planalto.gov.br 